\title{
FaKTOR YANG MEMPENGaRUHi KONVERSi LaHAN PERTANian StUdi KaSUS: KeCAMATAN JATEN, KABUPATEN KARANGANYAR
}

\author{
Yuniar Irkham Fadlli, Soedwiwahjono, Ana Hardiana \\ Program Studi Perencanaan Wilayah dan Kota, \\ Fakultas Teknik \\ Universitas Sebelas Maret, Surakarta \\ email: yuniar.irkham@gmail.com
}

\begin{abstract}
Surakarta City experienced population growth and rapid economic development, while land availability is limited so that the developments leading to suburban areas. Such as in Jaten that have a high-intensity agricultural land conversion caused by the high rate of population growth and the development of market mechanisms as a result of the economic development in Jaten. Jaten also has a high level of productivity of agricultural land. Therefore, needs to be studied further in Jaten why a lot of agricultural land conversion?

The method of this research is deductive. The data analysis technique used is qualitative by using crosstab analysis to determine an influence factor the conversion of agricultural land to the phenomenon the conversion of agricultural land in the district Jaten and descriptive analysis of qualitative to determine the factor that affect the conversion of agricultural land in Jaten.

Results of this study is factor that affect the conversion of agricultural land in Jaten include population growth caused by high birth rates, GDP District of Jaten where the sector processing industry is a sector basis, the price of land, farmers' preferences, availability of infrastructure and government policy.
\end{abstract}

Keywords: land conversion, agricultural land, birth rate

\section{PENDAHULUAN}

Pertumbuhan penduduk suatu wilayah yang mengalami peningkatan setiap tahunnya akan berpengaruh terhadap persediaan bahan pangan dan persediaan hunian baru. Semakin meningkat pertumbuhan penduduk suatu wilayah, maka kebutuhan akan hunian baru juga semakin meningkat sehingga permintaan akan lahan meningkat guna memenuhi kebutuhan akan hunian baru tersebut.

Perkembangan perekonomian suatu wilayah yang ditandai dengan peningkatan pendapatan regional (PDRB) menyebabkan munculnya banyak pembangunan infrastruktur pendukung kegiatan perekonomian seperti jaringan jalan, industri, dan sarana perdagangan (pusat perbelanjaan, pertokoan, dll). Menurut Adisasmita (2010), perkembangan perekonomian yang ditandai meningkatnya pendapatan perkapita akan diikuti oleh suatu penurunan dalam proporsi sumberdaya yang dimanfaatkan dalam pertanian (sektor primer) dan suatu peningkatan dalam industri manufaktur (sektor sekunder) dan kemudian dalam industri jasa (sektor tersier). Ini artinya bahwa perkembangan ekonomi membutuhkan lahan guna membangun infrastruktur perekonomian yang menyebabkan terjadinya konversi lahan di suatu wilayah.

Adanya kebutuhan lahan untuk hunian baru dan penyediaan infrastruktur perekonomian membuat harga lahan menjadi meningkat. Menurut Irawan (2005), ada dua hal yang mempengaruhi alih fungsi lahan, yaitu pembangunan kawasan perumahan atau industri dan peningkatan harga lahan. Peningkatan harga lahan itu sendiri nantinya dapat merangsang petani untuk menjual lahan pertaniannya. Artinya, semakin mahal harga suatu lahan maka akan semakin rawan juga lahan tersebut akan terkonversi. Jadi, harga lahan merupakan faktor eksternal yang sangat berpengaruh terhadap preferensi petani terkait dengan konversi lahan pertanian.

Wilayah Subosuka Wonosraten atau yang biasa disebut Solo Raya, merupakan kawasan strategis dengan Kota Surakarta sebagai pusatnya dan dikelilingi oleh wilayah-wilayah Urban Fringe di pinggiran Kota Surakarta. Kota Surakarta mempunyai sarana prasarana yang sangat memadai mulai dari transportasi, 
pendidikan, kesehatan dan perdagangan dan jasa. Hal ini memicu munculnya daya tarik yang sangat besar bagi masyarakat dari luar Solo Raya yang mengakibatkan terjadinya peningkatan jumlah penduduk dari tahun ke tahun. Peningkatan jumlah penduduk ini akan sangat berpengaruh terhadap penyediaan hunian baru, sedangkan ketersediaan lahan di Kota Surakarta terbatas. Keterbatasan lahan inilah yang membuat masyarakat yang mayoritas merupakan masyarakat pendatang mencari lahan untuk dijadikan hunian baru mereka di sekitar pinggiran Kota Surakarta. Hal ini yang mengakibatkan terjadi banyaknya konversi lahan pertanian di kawasan pinggiran Kota Surakarta contohnya adalah seperti yang terjadi di Kecamatan Jaten.

Kecamatan Jaten merupakan kecamatan yang terletak di pinggiran Kota Surakarta yang mempunyai rata-rata laju pertumbuhan penduduk tinggi, yaitu 2,01\% dari tahun 20042013 yang mengindikasikan bahwa kebutuhan akan hunian baru di Kecamatan Jaten juga tinggi. Mengacu pada RTRW Kabupaten Karanganyar Tahun 2013-2032, Kecamatan Jaten diarahkan menjadi 3 arahan pemanfaatan utama, yaitu pertanian lahan basah $(1.017,91$ $\mathrm{Ha})$, industri $(93,06 \mathrm{Ha})$ dan permukiman (1.714,26 Ha).

Kecamatan Jaten merupakan kecamatan yang masuk ke dalam wilayah Urban Fringe Kota Surakarta. Kota Surakarta yang mempunyai intensitas konversi lahan cukup tinggi. Menurut data dari BPS, Kecamatan Jaten mengalami penurunan luas lahan pertanian sebesar 66,47 Ha dalam kurun waktu antara tahun 2004-2013 (Kecamatan Jaten Dalam Angka Tahun 2004-2013, BPS). Penurunan luas lahan pertanian ini disebabkan oleh banyak faktor, terutama faktor perkembangan perekonomian dan pertumbuhan penduduk yang tinggi. Oleh karena itu, perlu dikaji lebih lanjut mengapa di Kecamatan Jaten terjadi banyak konversi lahan pertanian dan kira-kira apa saja faktor yang mempengaruhi, sedangkan rata-rata tingkat produktivitas lahan pertanian di Kecamatan Jaten juga cukup tinggi yaitu 7,347 Ton/Ha (Kabupaten Karanganyar Dalam Angka Tahun 2004-2013, BPS) serta menurut arahan RTRW Kabupaten Karanganyar Tahun 2013-2032,
Kecamatan Jaten termasuk dalam kawasan pertanian lahan basah.

Mengacu pada hal di atas, maka tujuan penelitian ini adalah untuk mengetahui faktorfaktor yang mempengaruhi terjadinya konversi lahan pertanian di Kecamatan Jaten. Oleh karena itu, didapatkan rumusan permasalahan dalam penelitian ini adalah apa faktor-faktor yang mempengaruhi terjadinya konversi lahan pertanian di Kecamatan Jaten?

\section{METODE}

\section{A. Ruang Lingkup}

Ruang lingkup wilayah penelitian yaitu Kecamatan Jaten yang merupakan salah satu kawasan di pinggiran Kota Surakarta. Kecamatan Jaten terdiri atas 8 desa dengan luas total 2.554,81 Ha. Wilayah tersebut yakni: Desa Suruhkalang, Desa Jati, Desa Jaten, Desa Dagen, Desa Ngringo, Desa Jetis, Desa Sroyo, dan Desa Brujul.

\section{B. Metode Analisis}

Penelitian ini menggunakan metode teknik analisis kualitatif dengan menggunakan analisis persilangan (cross tab) dan deskriptif kualitatif. Analisis yang digunakan terdiri atas tiga tahapan utama, yaitu:

1. Analisis Identifikasi Fenomena

Konversi Lahan Pertanian di

Kecamatan Jaten;

2. Analisis Pengaruh Faktor-faktor Konversi Lahan Pertanian terhadap Fenomena Konversi Lahan Pertanian di Kecamatan Jaten yang meliputi Laju Pertumbuhan Penduduk, Perkembangan Perekonomian (PDRB Kecamatan Jaten, Produktivitas Lahan Pertanian, Pendapatan Petani), Harga Lahan, Preferensi Petani, Ketersediaan Sarana-Prasarana (Jumlah Industri, Jumlah Kebutuhan Rumah, Jaringan Transportasi), Kebijakan Pemerintah;

3. Analisis Faktor-faktor Konversi Lahan Pertanian di Kecamatan Jaten untuk mengetahui faktor-faktor yang mempengaruhi konversi lahan pertanian di Kecamatan Jaten dan temuan-temuan dalam penelitian ini. 
III. HASIL DAN PEMBAHASAN

A. Analisis Identifikasi Fenomena

Konversi Lahan Pertanian di

\section{Kecamatan Jaten}

Dalam analisis ini menggunakan metode analisis deskriptif kualitatif guna mengidentifikasi fenomena konversi lahan pertanian di Kecamatan Jaten yang meliputi:

1. Pola Konversi Lahan Pertanian (X)

Berdasarkan peta perubahan penggunaan lahan di Kecamatan Jaten pada tahun 2004-2009 dan tahun 2009-2013, dapat diketahui bahwa perkembangan pola konversi lahan di Kecamatan Jaten selama kurun waktu 10 tahun adalah masih mengikuti pola perkembangan sebelumnya, yaitu banyak dipengaruhi oleh jalur transportasi yang dalam hal ini perkembangan tersebut mengikuti jalan arteri primer dan jalan kolektor yang melewati Kecamatan Jaten. Akan tetapi, karena lahan di sepanjang jalan tersebut sudah banyak yang terbangun dan harga lahannya yang tinggi, maka perkembangan pembangunan sekarang menuju lebih ke dalam mendekati kawasan permukiman yang sifatnya cenderung enclave (kantongkantong) dan sporadic. Hal ini dikarenakan masih banyaknya lahan pertanian di kawasan permukiman tersebut dengan harga yang cenderung lebih murah dibanding dengan harga lahan di pinggir/dekat jalan utama. Pertumbuhan penduduk yang pesat di Kecamatan Jaten juga bisa mempengaruhi terbentuknya pola konversi lahan di Kecamatan Jaten karena pertumbuhan penduduk menimbulkan dampak meningkatnya perumahan-permukiman baru yang kecenderungannya adalah mengkonversi lahan pertanian yang mempunyai aksesibilitas yang baik/tinggi. Jika dikaitkan dengan teori pola koversi lahan pertanian, maka pola konversi lahan pertanian di Kecamatan Jaten adalah sebagai berikut:

a. Pola konversi lahan gradual berpola sporadic (X1)

b. Pola konversi lahan sistematik berpola enclave (X2)

c. Pola konversi lahan sebagai respon atas pertumbuhan penduduk (population growth land conversion) (X3)

d. Pola konversi lahan multi bentuk/tanpa bentuk (X7)

2. Jenis Perubahan Penggunaan Lahan (Y)

Jenis perubahan penggunaan lahan di Kecamatan Jaten berdasarkan peta hasil digitasi GIS dengan dibantu citra satelit Kecamatan Jaten dari google earth mempunyai kecenderungan perubahan ke arah perumahan-permukiman dan industri dengan luasan yang bisa diukur.

3. Luasan Perubahan Penggunaan Lahan (Z)

Luasan perubahan penggunaan lahan di Kecamatan Jaten selama kurun waktu 10 tahun menunjukkan tanda positif (mengalami kenaikan). Luasan perubahan penggunaan lahan secara total adalah 96,464 Ha dengan rincian 40,41 $\mathrm{Ha}$ menjadi perumahan-permukiman dan 56,054 Ha menjadi industri berdasarkan hasil digitasi GIS dan dibantu dengan citra satelit google earth.

\section{B. Analisis Pengaruh Faktor-faktor} Konversi Lahan Pertanian terhadap Fenomena Konversi Lahan Pertanian di Kecamatan Jaten

Dalam analisis ini menggunakan metode analisis persilangan (cross tab) antara faktor konversi lahan dan fenomena konversi lahan pertanian guna mengidentifikasi bagaimana faktor tersebut bisa mempengaruhi terjadinya fenomena konversi lahan pertanian di Kecamatan Jaten.

1. Pengaruh Laju Pertumbuhan Penduduk Terhadap Konversi Lahan Pertanian di Kecamatan Jaten Berdasarkan hasil analisis diketahui bahwa laju pertumbuhan penduduk berpengaruh positif terhadap 
konversi lahan pertanian. Laju pertumbuhan penduduk mempengaruhi terbentuknya pola konversi lahan sebagai respon atas pertumbuhan penduduk (population growth land conversion, X3) dan mempengaruhi konversi lahan pertanian menjadi perumahanpermukiman dengan luas 40,41 Ha.

2. Pengaruh Perkembangan PDRB Kecamatan Jaten Terhadap Konversi Lahan Pertanian di Kecamatan Jaten Berdasarkan hasil analisis diketahui bahwa perkembangan PDRB Kecamatan Jaten berpengaruh positif terhadap fenomena konversi lahan pertanian di Kecamatan Jaten. Perkembangan PDRB Kecamatan Jaten mempengaruhi konversi lahan pertanian menjadi industri dengan luas $56,054 \mathrm{Ha}$.

3. Pengaruh Produktivitas Lahan Pertanian Terhadap Konversi Lahan Pertanian di Kecamatan Jaten

Berdasarkan hasil analisis diketahui bahwa produktivitas lahan pertanian tidak mempunyai pengaruh terhadap konversi lahan pertanian di Kecamatan Jaten.

4. Pengaruh Pendapatan Petani Terhadap Konversi Lahan Pertanian di Kecamatan Jaten

Berdasarkan hasil analisis diketahui bahwa pendapatan petani tidak mempunyai pengaruh terhadap konversi lahan pertanian di Kecamatan Jaten.

5. Pengaruh Harga Lahan Terhadap Konversi Lahan Pertanian di Kecamatan Jaten

Berdasarkan hasil analisis diketahui bahwa harga lahan berpengaruh positif terhadap konversi lahan pertanian di Kecamatan Jaten. Harga lahan mempengaruhi terbentuknya pola konversi lahan gradual berpola sporadic (X1) dan sistemik berpola enclave (X2). Harga lahan juga mempengaruhi konversi lahan pertanian menjadi perumahan- permukiman dan industri dengan luas total 96,464 Ha.

6. Pengaruh Preferensi Petani Terhadap

Konversi Lahan Pertanian di

Kecamatan Jaten

Berdasarkan hasil analisis diketahui bahwa preferensi petani berpengaruh positif terhadap konversi lahan pertanian di Kecamatan Jaten. Preferensi petani mempengaruhi terbentuknya pola konversi lahan gradual berpola sporadic (X1) dan sistemik berpola enclave (X2). Harga lahan juga mempengaruhi konversi lahan pertanian menjadi perumahanpermukiman dan industri dengan luas total $96,464 \mathrm{Ha}$.

7. Pengaruh Jumlah Industri Terhadap Konversi Lahan Pertanian di Kecamatan Jaten

Berdasarkan hasil analisis diketahui bahwa jumlah industri berpengaruh positif terhadap fenomena konversi lahan pertanian di Kecamatan Jaten. Jumlah industri mempengaruhi konversi lahan pertanian menjadi industri dengan luas 56,054 $\mathrm{Ha}$.

8. Pengaruh Jumlah Kebutuhan Rumah Terhadap Konversi Lahan Pertanian di Kecamatan Jaten

Berdasarkan hasil analisis diketahui bahwa jumlah kebutuhan rumah berpengaruh positif terhadap fenomena konversi lahan pertanian di Kecamatan Jaten. Jumlah kebutuhan rumah mempengaruhi konversi lahan pertanian menjadi perumahan permukiman dengan luas 40,41 Ha.

9. Pengaruh Tingkat Aksesibilitas Terhadap Konversi Lahan Pertanian di Kecamatan Jaten

Berdasarkan hasil analisis diketahui bahwa tingkat aksesibilitas berpengaruh positif terhadap konversi lahan pertanian di Kecamatan Jaten. Tingkat aksesibilitas mempengaruhi terbentuknya pola konversi lahan multi bentuk/tanpa bentuk (X7) dan mempengaruhi konversi lahan pertanian menjadi perumahan- 
permukiman dan industri dengan luas total 96,464 Ha.

10.Pengaruh Kebijakan Pemerintah Terhadap Konversi Lahan Pertanian di Kecamatan Jaten

Berdasarkan hasil analisis diketahui bahwa kebijakan pemerintah, dalam hal ini adalah RTRW Kabupaten Karanganyar berpengaruh positif terhadap konversi lahan pertanian di Kecamatan Jaten. Kebijakan pemerintah mempengaruhi konversi lahan pertanian menjadi perumahanpermukiman dan industri dengan luas total 96,464 Ha.

\section{Analisis Faktor-faktor yang Mempengaruhi Konversi Lahan Pertanian di Kecamatan Jaten}

Dalam analisis ini menggunakan metode analisis deskriptif kualitatif guna mengetahui faktor-faktor apa yang mempengaruhi konversi lahan pertanian di Kecamatan Jaten dan menemukan beberapa temuan-temuan dalam penelitian ini berdasarkan hasil analisis pengaruh faktor-faktor konversi lahan pertanian terhadap fenomena konversi lahan pertanian di Kecamatan Jaten.

Berdasarkan hasil analisis, dapat diketahui bahwa faktor-faktor yang mempengaruhi konversi lahan pertanian di Kecamatan Jaten adalah sebagai berikut:

1. Laju Pertumbuhan Penduduk

Tingginya laju pertumbuhan penduduk di Kecamatan Jaten disebabkan oleh pertumbuhan alami yang tinggi, yaitu kelahiran.

2. PDRB Kecamatan Jaten

PDRB Kecamatan Jaten mempunyai sektor basis berupa sektor industri pengolahan yang mendominasi mencapai $80 \%$ dari total pendapatan. Sektor pertanian dalam PDRB Kecamatan Jaten sebenarnya mengalami peningkatan dari tahun ke tahun. Akan tetapi, karena sektor pertanian bukan merupakan sektor basis sehingga fenomena konversi lahan pertanian di Kecamatan Jaten masih tetap terjadi.

3. Harga Lahan
Tingginya harga lahan di Kecamatan Jaten disebabkan oleh tingginya permintaan lahan untuk jenis penggunaan lahan berupa perumahan-permukiman, kegiatan industri dan perdagangan-jasa.

4. Preferensi Petani

Preferensi petani terkait fenomena konversi lahan pertanian di Kecamatan menunjukkan positif karena petani tertarik akan tingginya harga lahan di Kecamatan Jaten. Petani menjual lahan pertaniannya yang kemudian uang hasil menjual lahan pertanian tersebut digunakan untuk membeli lahan pertanian kembali di tempat yang agak jauh karena harga lahannya yang masih lebih murah sehingga petani masih mempunyai simpanan uang hasil menjual lahan pertaniannya.

5. Ketersediaan Sarana-Prasarana Pengembangan kawasan perumahanpermukiman baru di Kecamatan Jaten sangat terkait dengan terbatasnya lahan di Kota Surakarta sehingga perkembangan mengarah ke kawasan pinggiran, salah satunya adalah Kecamatan Jaten.

Munculnya kawasan industri di Kecamatan Jaten selain diakibatkan oleh adanya perkembangan mekanisme pasar, juga diakibatkan oleh adanya kebijakan terkait proses industrialisasi di Kecamatan Jaten sejak zaman pemerintahan Orde Baru lewat kebijakan berupa Pelita (Pembangunan Lima Tahun) yang berfokus pada pembangunan perekonomian di Indonesia melalui pembangunan infrastruktur, peningkatan sektor pertanian dan industri, peningkatan kesejahteraan masyarakat (pendapatan perkapita), dll.

6. Kebijakan Pemerintah

Kebijakan pemerintah yang dimaksud adalah RTRW Kabupaten Karanganyar.

a. Terkait dengan karakteristik sektor basis, RTRW Kabupaten 
Karanganyar menjelaskan bahwa sektor basis di Kecamatan Jaten adalah sektor industri pengolahan karena mempunyai nilai LQ tertinggi sehingga penetapan arahan pengembangan di Kecamatan Jaten adalah untuk kawasan industri besar dan menengah yang sifatnya pemantapan, sedangkan untuk pengembangan kawasan industri lebih lanjut akan diarahkan ke Kecamatan Gondangrejo

b. Terkait dengan arahan kawasan permukiman perkotaan dan perdesaan, RTRW Kabupaten Karanganyar menjelaskan bahwa pengembangan permukiman perkotaan juga dipengaruhi oleh keberadaan ruas-ruas jalan di Kabupaten Karanganyar terutama di ruas jalan batas Kota SurakartaPalur-Kebakkramat-batas

Kabupaten Sragen, ruas jalan Karanganyar-Jumapolo-

Jatipuro-batas Kabupaten Wonogiri, ruas jalan Karanganyar-MojogedangKerjo-batas Kabupaten Sragen dan ruas jalan PalurKaranganyar-Karangpandan-

Tawangmangu-batas Kabupaten Magetan Jawa Timur. Kawasan permukiman perkotaan di Kabupaten Karanganyar akan tersebar di masing-masing pusat kecamatan serta di sepanjang jalur Palur-Sragen termasuk di dalamnya Kecamatan Gondangrejo, Jaten dan Kebakkramat, serta Kecamatan Tasikmadu dan Karanganyar. Hal ini dibuktikan dengan perkembangan di Kecamatan Jaten selama kurun waktu 10 tahun yang masih mengikuti pola perkembangan sebelumnya, yaitu banyak dipengaruhi oleh jalur transportasi di mana dalam hal ini perkembangan pembangunan tersebut mengikuti jalan arteri primer dan jalan kolektor. Perkembangan sekarang ini yang menuju lebih ke dalam mendekati kawasan permukiman karena masih banyak lahan pertanian di kawasan permukiman tersebut dengan harga yang cenderung lebih murah sedangkan lahan di sepanjang jalan tersebut sudah banyak yang terbangun dan harga lahan yang tinggi.

\section{KESIMPULAN}

Berdasarkan hasil penelitian yang telah dilakukan, diketahui bahwa faktor yang mempengaruhi konversi lahan pertanian di Kecamatan Jaten yakni laju pertumbuhan penduduk yang diakibatkan oleh tingkat kelahiran, PDRB Kecamatan Jaten di mana sektor industri pengolahan merupakan sektor basis, harga lahan, preferensi petani, ketersediaan sarana-prasarana (jumlah industri, jumlah kebutuhan rumah, jaringan transportasi) dan kebijakan pemerintah.

Rekomendasi dari hasil penelitian ini yakni membuka peluang adanya penelitian lanjutan terkait dengan faktor apa saja yang mempengaruhi konversi lahan pertanian dan membuka peluang adanya studi evaluasi terkait dengan kebijakan yang dikeluarkan pemerintah daerah Kabupaten Karanganyar serta studi-studi lanjutan yang terkait dengan materi studi.

\section{REFERENSI}

Adisasmita, Rahardjo, 2010. Pembangunan Kawasan dan Tata Ruang. Graha Ilmu.Yogyakarta

Irawan, Bambang, 2005. Konversi Lahan Sawah: Potensi Dampak, Pola Pemanfaatannya dan Faktor Determinan. Jurnal.Pusat Penelitian dan Pengembangan Sosial Ekonomi Pertanian.Bogor

Kabupaten Karanganyar Dalam Angka. 20042013.BPS.Kabupaten Karanganyar 
Kecamatan Jaten Dalam Angka.2004-

2013.BPS.Kabupaten Karanganyar

RTRW Kabupaten Karanganyar 2013-

2032.Bappeda.Kabupaten Karanganyar 